\title{
INDEPENDENT OPERATIONS, OBLIGATORY OPERATIONS AND CHALLENGE OF OPERATOR PROVISIONS IN JOINT VENTURE AGREEMENTS
}

\author{
W. G. BROWN*
}

\begin{abstract}
Although the concept of a joint venture is one of joint action, joint venture agreements in use in the oil and gas industry contain provisions for independent operations. This article discusses the need for independent operations clauses, the types of independent operations clauses, including obligatory operations clauses, the types of penalties and general problems which should be considered in the drafting of independent operations clauses. The article concludes with an analysis of the challenge of operator provisions in joint operating agreements.
\end{abstract}

Although the expression "joint venture" contemplates a joint action, provisions for independent operations, obligatory operations and challenge of operator found in most joint venture agreements provide for those situations where the parties to the agreement have not been able to agree upon a common course of action.

\section{A. INDEPENDENT OPERATIONS}

1. Purpose

In examining provisions for independent operations, regard must be taken of the purpose to be accomplished and it appears that there are two chief reasons for such provisions. First, as a result of differences of technical opinion, budgets or for other reasons, there must be mechanics available to the parties to allow a party to take independent action. Secondly, that party which has borne the entire cost of the operation, which was designed to enhance the value of or evaluate the joint property, should be provided with a reward commensurate with the risk taken.

\section{Types of Independent Operations}

The type of independent operation that first comes to mind is the independent drilling of wells. Most agreements in use in the industry make a distinction between voluntary drilling and obligatory operations (the latter being dealt with separately later in this paper) and it is becoming increasingly common to find distinctions made between development, exploratory and validating wells with different penalties for failure to participate in each type of well. The distinction between development and exploratory wells is generally expressed as a matter of distance from an existing producer or a well capable of production. However, in making the distinction, the definition must not only make reference to the distance, but also must have regard to the formations in question. For example, if a development well is defined as one within a mile or less from existing production and the well in question is located within a mile of Viking production at 3,000 feet, but is drilled to 6,000 feet where it encounters Devonian production and there is no

- Barrister and Solicitor, Saucler, Jones, Peacock, Black, Gain, Stratton and Laycraft, Calgary, Alberta. 
other well within a mile with Devonian production, this well should be classed as an exploratory well insofar as the Devonian production is concerned.

Once having made this distinction between development and exploratory wells, it follows that a well may be partly developmental and partly exploratory, and this further distinction can lead to complications. In the example given, assuming that the well drilled had no production in the Viking, but was successfully completed in the Devonian, what costs are to be recovered and what penalty is to be applied? Can it be reasonably argued that since the well obtained no Viking production, the independent operator must treat that portion of the cost in going to the Viking as a write-off and receive his exploratory penalty of only that portion of the cost attributable to the Devonian. Surely this is not reasonable in that the Viking must be penetrated to reach the Devonian. On the other hand, in the reverse situation where the Viking is productive, but the Devonian is not, it seems clear that the independent operator should receive his development penalty on only those costs attributable to drilling to the Viking and must write-off his costs in going down to the Devonian and plugging-back to the Viking. This same problem can arise even when no distinction is made between development and exploratory wells where, for example, the independent operator drills a well to 10,000 feet, but finally completes it at 3,000 feet, the question arises as to whether the independent operator is entitled to recovery of costs and penalty on the drilling costs for the last 7,000 feet and his costs of plugging-back to 3,000 feet.

A related matter which should be considered when drafting independent drilling clauses is whether provision should be made for allowing participation at less than total depth. For example, A gives notice of his intention to go to 12,000 feet. B thinks there is nothing of interest at 12,000 feet, but does think there is a good prospect at 8,000 feet. C does not have sufficient funds to go to either depth, but is interested in participating to 4,000 feet. This would appear to be a quite useful provision whereby $B$ and $C$ can participate to less than total depth, but considerable difficulty can be expected in attempting to draft a workable and equitable provision.

Now dealing with the third type of well mentioned above, namely a validating well, validating wells are frequently singled out from other kinds of wells because the consequence of a failure to drill a validating well is much like the consequence of a failure to drill an obligation well, that is, loss of land. A problem for which there does not appear to be any really satisfactory solution arises in the situation where both parties to the agreement covering a drilling reservation are prepared to drill a validating well, but cannot agree on the location due to differences of geological opinion, or for other reasons. One solution considered is to provide that the party not participating in the first well would not forfeit its interest in the reservation if it drilled its well at its location within a certain specified time. However, if the first well is productive, a second well cannot be drilled on the reservation, but rather a lease selection must be made. In the result, the lease selection would have to be made to include a location for the well proposed by the party 
not participating in the first well, and this arrangement could well work a hardship on the party which had drilled the first well.

Turning now to independent operations other than the drilling of wells, generally speaking, joint venture agreements currently in use do not contemplate operations other than those in connection with a well designed to be a producer. Since the discovery of the Rainbow Field there has been increased emphasis on seismic, and the question arises as to how a party conducting an independent seismic operation should be rewarded. In the case of an independently drilled well, the reward can be tied to that particular well whether it be in the form of a penalty out of production, a cash penalty or an acreage penalty. In the case of a seismic operation, it can be provided that the non-participating party must pay a premium to obtain the information, but at the same time it seems quite possible that the non-participant could sit back and await the other party's suggestion as to a well location and thereby indirectly receive the benefit of the seismic operation.

A problem can also arise in connection with the drilling of injection wells prior to unitization. It is not possible to reward the independent operator with production from or acreage attributable to that well, but is it equitable to charge the penalty against other joint production even though that other joint property may have benefited directly from the injection facility?

\section{Types of Penalties}

There are three usual kinds of penalties-production, cash or acreage. Although a great deal can not be said about penalties, a few points should be mentioned. First in connection with both production and cash penalties, careful consideration should be given as to the costs upon which the penalties should be charged. For example, since normally no real risk is involved in the installation of surface equipment, these costs should be subject only to simple recovery, rather than being subjected to a higher percentage penalty charged on the down hole costs. Secondly, upon recovery of a penalty out of production, should the non-participant automatically back-in or should he have an election? It would appear desirable that the back-in not be automatic as the nonparticipant may well be backing-in to a "pig in a poke". Thirdly, in respect to acreage penalties, the independent operator should be rewarded only if his decision turned out to be right, that is, only if he obtains production. In the case of production or cash penalties, a reward will be received only in the event of production, and surely the same should be true of acreage penalties.

\section{General Problems in Independent Operations Clauses}

Before leaving the topic of independent operations, there are a few other general points that might be mentioned. In the case of a production penalty, the question arises as to who should operate during the recovery period. Some agreements provide that immediately upon encountering production, the operator is to take over, while other provide that the independent operator will operate until recovery has been 
accomplished. Most agreements provide that the operator is automatically discharged if he disposes of all of his interest in the lands, presumably on the basis that he should be spending his own dollars at the same time as he is spending another party's money. For the same reason, it would appear desirable that the independent operator should have the right to operate the well during the recovery period if he so elects rather than having the operator automatically take over. It should be mentioned that if the operator is not participating in a well evaluating posted acreage, the operator should clearly not operate.

A point that is not always covered in connection with deepening, reworking, or plugging-back is that the non-participant should be obliged to put up what would have been his share of the abandonment costs had the well been abandoned at that point.

Some parties as a matter of policy wish to have a limit on the number of independent drilling operations which can be conducted during any given period; this may or may not be desirable in all situations, but it should always be provided that no new operation may be commenced until the non-participant has received all information from the last operation in order that he be in a position to judge as to whether to participate in the newly proposed operation. In this same connection of timing of operations, some agreements provide that the independent operations may not be commenced until the notice period for election to join has expired, and one cannot help but wonder why that provision is made. It seems that the independent operator should be able to choose whether he wishes to assume the risk of another party "riding him down the hole".

With the increasing frequency of unitization, a final point that should be kept in mind in production penalty situations is a provision for the sharing of equalization of investment costs during the recovery period.

\section{B. OBLIGATORY OPERATIONS}

\section{Definition}

This is a somewhat contentious subject in the industry, as there are some lawyers who take the view that there is no such thing as an obligatory operation, or, even if such an operation does exist, that it is impossible to determine precisely when it has arisen. Lawyers who subscribe to this view generally take the position that what others would call an obligation well should be treated the same as any other kind of independent well.

Assuming that there is such a thing as an obligatory well, the question then arises as to how it should be defined. The industry has defined it as "a well which is required to be drilled pursuant to the terms of the leases or any order or regulation applicable to the joint lands, waiver of which requirement cannot be obtained by payment of compensatory royalty, negotiation, or other means", "a well that is required to be drilled pursuant to the documents of title or any laws (unless the obligation is not being enforced) even though the time for commencement may be extended", and "a well which is required to be commenced and drilled on the said lands pursuant to the said leases or the regulations applicable thereto, and which if not drilled will result in the forfeiture of all or a 
portion of the said lands." In spite of these precise definitions, it would appear that there still could be some doubt as to whether an obligation exists in any particular case. Is it not possible that an appropriate cash payment offered to the party attempting to enforce the obligation could cancel the obligation or at least, defer it? If there is this alternative of offering the cash payment or making any other arrangement to cancel or defer the obligation, can it be said that there is an obligation well situation?

\section{Purpose}

In addition to having the same purposes as those for voluntary independent wells, namely, to permit independent action and to establish an appropriate reward for such independent action, the obligatory operations clause should provide for an orderly and reasonable method of dealing with the obligation. That is, since presumably no party to the agreement is anxious to drill the well, or the obligation would not have arisen, it would appear that the first responsibility of the operator would be to seek methods, other than drilling, for obtaining release from obligation. The operator should first attempt to negotiate release on terms acceptable to the parties and, failing this, attempt to farm out the lands on acceptable terms. If no other arrangement can be made, then independent drilling should be invoked with an appropriate penalty.

\section{Types of Penalties}

The penalty most commonly used in the industry for the drilling by less than all parties of an obligation well (such as an offset) is forfeiture by the non-participant of its interest in the lands, which said lands would have been lost had the well not been drilled. Some agreements provide for a production penalty, usually double the percentage provided for in voluntary independent operations. If we accept the proposition that there is such a thing as an obligatory well, which if not drilled would result in forfeiture of all or a portion of the jointly owned lands, then it would appear a forfeiture of interest by the non-participant is the only appropriate penalty.

One further feature which should be kept in mind in dealing with obligatory operations is the situation where no party to the agreement wishes to drill the well as an obligation well and no release of the obligation can be negotiated. In these desperate circumstances where no relief of any form can be obtained, provision should be made for the operator to drill the well at the joint expense of the parties.

\section{CHALLENGE OF OPERATOR}

\section{Purpose}

Practically all joint venture agreements in use in the industry today provide for not only an automatic discharge of the operator for such reasons as bankruptcy of the operator, disposition by the operator of all or a majority of his interest and other reasons, but the agreements also provide for a challenge of the operator's position. Here again, the draftsman when considering these challenge provisions must have regard to the primary purpose of the clause. The basic purpose must be to 
insure sound and prudent operations at competitive rates, while at the same time providing for a reasonable degree of continuity of operation.

\section{Types of Challenges}

The basis of challenge varies considerably among agreements currently in use; probably the most common being a dissatisfaction with one or more of the operational procedures. Other agreements provide for a challenge to be made on the basis of financial improvement which is sometimes expressed as a certain minimum improvement on the operator's charges over which he has control, such as overhead. In some cases a challenge on the basis of financial improvement stands alone, and at other times it can be combined with a challenge on other terms as well.

Both the challenge based upon operational improvement and the challenge based upon financial improvement have disadvantages in application. In the case of a challenge upon the basis of operational improvement, excepting the most obvious cases, how does the challenger show that his proposal is an improvement, and what is to prevent him from making a proposal that is, in fact, not an improvement at all? Is the operator to be forced into a position of meeting terms that are really not as desirable for the joint operation as those under which he is presently conducting his operations? In the case of a challenge on the basis of financial improvement, the obvious argument is that any operation can be conducted at less cost if it is not done as well.

In addition to these disadvantages to the operation generally, there are drawbacks from the challenger's point of view. It seems likely that when the challenge is made, whether it be based upon a complaint of operational procedures or financial improvement, there would be questions raised as to whether the challenge was warranted, whether the proposal made is, in fact, an improvement and other rather pointless debate. It would appear that the problem could be resolved by providing for preemptory challenge with the provision, of course, that the challenger would have to operate on no less favourable terms than those presently governing the operation. This procedure is apparently used to a considerable extent in the United States, but it is not frequently encountered in Canada. 